assistants. The same thorough disinfection, ventilation, and cleanliness are observed bere as in the bath establishments. The "luoghi commodi" (convenient places) have been constructed outside the main building but communicate with it by means of well-ventilated covered passages. These closets are furnished with every modern sanitary safeguard. The food is simple but of the best quality and is furnished even to the poorer patients in great abundance. The soup, which I tried npon Professor Baistrocchi's recommendation, was most savoury and nutritious. The curative results accomplished in the stnatorium, chiefly in scrofulous and gynæcological maladif $s$ have been so brilliant that they merit more careful study ar $d$ discussion. These poor patients have supplementary trea ment by massage, electricity, medical gymnastics, \&c., when necessary.

Patients care little for the why and wherefore of curative results, passionately desiring to be healed of their infirmities, with as much amusement as may be during the process. They never rise above empiricism and only glorify results, which is natural and commendable. But we must solve, if possible, the difficult problem of the modus operandi of these complex remedies upon infinitely more complicated organisms. In no other way can we hope to prescribe them with absolute confidence in all case and in all circumstances. Upon the threshold of this investigation we must acknowledge that chemistry has hitherto failed to give us a complete explanation of the favourable effect of these waters. Brine baths, in conjunction with various douches, electricity, massage, applications of hot mud, \&c., produce analogous but far less powerfully curative local effects than the Salsomaggiore waters employed in the same way. The cause of this more powerful and speedy action was supposed to be due to the absorption of t e salts of lithia, bromine, strontium, and especially iodine (and perhaps certain organic sulphur com. pounds), contained so largely in the latter waters. The most careful tests, however, have hitherto failed to follow these substances from the unbroken skin through the organism, no traces of the same having been discovered in the excretions after Salsomaggiore baths of various strengths, duration, and temperatures. It has been asserted that cataphoresis would explain the supposed absorption. Elevey says that the effect of contact in mineral water baths reinforced by the natural electrical currents is more than sufficient to explain the increased tissue metamorphosis which occurs. At any rate we know that these waters, as employed at Salsomaggiore, do greatly accelerate tissue metumorphosis and that by means of various inhalations the more soluble salts are absorbed through the mucous membrane, thus contributing to enhance curative results.

Almost all varieties of inflammatory adhesions and deposits are liquefied and absorbt $d$; ulcers, bone ab-cesses, suppu rating glands, lupus vulgaris, and other tuberculous lesions are healed; chronic naso-pharyngeal and tracheo-bronchial catarrh, and even czæna, are greatly benefited and often cured; and various secondary and tertiary syphilitic local lesions are much relieved and frequently removed. The various dyscrasiæ accompanying the e maladies are rapidly and surely corrected and the organism is placed in more prosperous relation with its environment. Certain amuse ments are provided at the spa in the way of music and song, light operas, and theatrical representations which help to pass the time more agreeably, although they cannot rival the beanty and charm of this interesting folk and their wonderful country.

In this picturesque section of Lombardy, with its splendid seasonable climate and radiant azure sky, every footstep discovers some trace of Ruman baths or other evidence o the extraordinary intelligence and energy of that miyhty classic race. Mediæval art has also left enchanting monaments upon every hand-great castles and lordly villas, here and there vast convents and monasteries crowning noble heights, and over all the indescribable atmosphere of brave old Italy, the Madonna country of the world.

A Centenarian. The Hon. David Wark, of Fredericton, New Brunswick, celebrated his 100th birthd,$y$ on $F \in h .19 \mathrm{~b}$ and received the cabled congratulations of King $\mathbf{E}+$ ward on the occasion. He is the oldest pub ic man in the British Empire and possibly in the world. Mr. Wark was born in Londonderry, Ir+land, in 1804. He went to Canada in 1825, entered the New Broncwick Legi-lature in 1837, and has been a senator of the Dominion continuously since the Confederation.

\section{A CASE OF GANGRENE OF THE RIGHT FOOT OCCURRING IN THE NEWLY BORN.}

By DIGBY COTES-PREEDY, M.A. CANTAB., L.S.A. LOND., LATE HOUSE PHYSTCIAN AT' ST. GEORGE'S HOSPITAT.

ON August 27th, 1903, a married woman, aged 44 years, was confined of a full-term female child. She was the mother of ten children who are all alive and also had had three miscarriages. At every confinement she had suffered from rather severe post-partum hæmorrbage but otherwise she generally enjoyed good health. In June, 1903, she had a fall from an omnibus step on to her right side and a fortnight later she fell down some stairs in her house, again alighting on her right side. The confinement was superintended by an experienced midwifery student from St. George's Hospital. The presentation was of the right occipito-anterior variety. Strong pains commenced at 9 A.M., the child being born at 710 P.M. Some difficulty was met with on account of a slight impacticn of the shoulders. The umbilical cord was found to be twisted twice round the neck. The right foot was the last to be born, but there was no trace of amniotic bands around it. Owing to the deep cyanosis of the child artificial respiration was resorted to for the space of ten minutes; this restored the breathing but at no time was respiration forcible in character. The general state of the infant continuing unsatisfactory and the condition of the right foot, which is described hereafter, being such that hospital treatment was indicated, a relative was requested to take the child to the hospital for admission, but on arrival at 10.30 P.M. I found that the infant had apparently been dead for about te $n$ minutes.

The post-mortem examination was made 38 hours after death by Dr. T. R. Whipham, to whom I am indebted for the use of the following notes. The body was fat. well-developed, and of rather large size. The skin of the lower half of the right leg in front, of the dorsum of the foot, of the dorsal aspect of the first toe, of part of the dorsal aspects of the second, fourth, and fifth toes, and of the inner balf of the under surface of the foot, including that of the great toe, was intensely red and devoid of its epidermal structures, being, in fact, in a state of early gangrene. On the dorsum of the foot the area corresponding to the cutaneons distribution of the anterior tibial nerve was specially affected. The gangrene, which was moist, affected only the skin and subcutaneous structures, the deeper parts being healthy; its line of demarcation was sharply defined. No macroscopic cause for the condition was found there were no pressure on the arteries or nerves, no blocking of the vessels of the limb from the aorta to the foot, and no change to the naked eye in either the anterior or posterior tibial nerves. Microscopically, the posterior tibial nerve was normal. A portion of what was removed as the anterior tibial nerve proved to be the artery. This also was normal. The outline of the gangrene was so irregular that it seemed hardly likely to have been caused by intra-nterine pressure. The umbilical cord was attached and healthy. There were neither external signs of injury nor fractures of the bones. There was no fracture of the cranium. At the ba.e of the brain on the left side there was consideranle hæmorrhage nnder the dura mater but the source of the bleeding conld not be determined. The brain weighed 12 ounces. All the vessels on the surface and in the substance were congerted but nothing else abnurmal was found. The langs in situ were not fully expanded. The edges of both were very emphysematous and in places there was partial atelectaris, small pieces cut from both only ju $t \mathrm{t}$ ating in water. The right side of the heart was slightly dilated, otherwi.e the viscus was normal. The other organs of the body showed no abnormality.

This case I have deemed of interest nwing to its rarity. A search thr ugh many works has elicited nothing to explain adequately the cause of the gangrene-even Ballintyne's Ante-Natal Pathology afforded no assistance Several theories have suggested themselves, $\mathrm{knch}$ as amniotic bands, pre-sure effects produced in utero, the action of bacteria, and, lastly, the increased blood pressure produced by the exce-sive contraction of the womb during the labour which the minute 
blood-vessels were unable to cope with-this reason I gave to the deputy coroner ( $\mathrm{Mr}$. R. Henslowe Wellington, M.R.C.S. Eng.) in order to account for the subdural bæmorrhage-but they cannot be substantiated sufficiently by the facts at my disposal. The two accidents experienced by the mother prior to the birth of the child seem to offer the only clue to the explanation of a condition which on account of its rare occurrence deserves to be recorded.

I have to acknowledge the kind permission of Dr. A. F. Stabb to publish this case.

Croydon.

\section{Climital 算otes:}

\section{MEDICAL, SURGICAL, OBSTETRICAL, AND THERAPEUTICAL.}

\section{NOTE ON A CASE OF (?) TUBERCULOUS MENINGITIS.}

\section{By William R. Bates, L.R C P., L.R.C.S. IREL.}

THE following case is, I think, of sufficient clinical interest to be recorded. The patient, who was a female, aged 19 years, was first seen by me at my house on Dec. 4th, 1900. She complained of feeling weak and tired, her appetite was capricious, there had been a gradual loss of flesh all the summer with increasing debility, and she had a large, painful, lymphatic swelling on the right side of the neck. 'Her temperature, taken in the mouth, was normal, her heart sounds were healthy, and there were no abnormal physical signs in the chest or the abdomen. She was ordered to paint the neck with a combination of collodion and belladonna and a pill containing arsenate of iron, nux vomica, and reduced iron was given.

I was called in to see her on Dec. 13th. She had been in bed from the 9th ; intense headache commenced on the 10th but she had tried to get up on the 12th and was obliged to return to bed at once; vomiting commenced about $11 \mathrm{~A} . \mathrm{M}$. on that day. When seen by me her temperature was $103^{\circ} \mathrm{F}$. and her pulse rate was 72 ; her respirations were quick; she had intense headache and intolerance of light with frequent vomiting; the pupils were equal and dilated; the bowels were constipated; there was no retraction of the abdomen. Her mistress was told that the illness was most probably meningitis and the girl was removed to her own home which, fortunately, was not far distant, where she could be well nursed. A powder containing ten grains of phenacetin and six grains of mercurous chloride was given. On the 14th she was worse. There was constant meningeal cry with marked retraction of the head; the vomiting still continued and occasional delirium was noticed. The patient's head was shaved, a large blister was applied to the nape of the neck, iodide of potassinm in ten-grain doses with 15 grains of bromide of potassium was given every four hours, and mercurial ointment was rubbed into the axillæ and the groins night and morning. Her temperature ranged between $101^{\circ}$ and $103^{\circ}$ and the pulse was markedly slower. On the 15th the patient's condition was much the same but the pupils were sluggish in acting; her temperature was about the same and her pulse rate was 56 ; sobbing respiration was also noticed. On the 16th there was paralysis of the external rectus of the right eye. The discs were examined and marked neuritis was found but no tubercle was seen in the choroid. Vomiting still continued but was not so incessant. Tache cérébrale was well marked. On the 17th she was seen by me in consultation with my friend Dr. J. N. Richardson who agreed as to the diagnosis of meningitis, most probably of tuberculous origin, and an unfavourable prognosis was given. There was marked diplopia and both external recti were now affected; the pyrexia continued and the acuteness of vision was distinctly lessened. On the 18th the girl's condition was pretty much the same and it continued so through the $19 \mathrm{~h}$. On the $20 \mathrm{th}$ her temperature was normal in the morning, there was much less headache, and the vomiting which had gradually been subsiding for two or three days now ceased. In the evening her temperature was $994^{\circ}$ and thereafter she steadily improved and gained flesh. From this time there was practically no pyrexia but double vision lasted for more than a fortnight and the squint did not quite disappear until May, 1901, when the girl was well enough to pursue her occupation.

What was the condition which gave rise to this train of symptoms? There can hardly be any difference of opinion as to some form of meningitis having been present. As there was no history of injury, middle-ear disease, or influenza the most probable varieties would be either (1) a septic form occurring in the course of some concurrent disease which I think need not be further considered, or (2) a specific form of the disease as the syphilitic or tuberculous Against the first of these two causes is the objection that by the most careful examination and minute inquiries as far as they could be made without hurting the patient's feelings or those of her friends no evidence of primary sore secondary trouble, or congenital affection could be found and I am left to fall back on the theory that the exciting cause of the illness was the tubercle bacillus. The history of increasing debility, the gradual loss of flesh, the affected lymphatic glands of the neck, and the age of the patient incline me to take this view, although it may be argued that from the manner in which the disease gave way to the treatment by mercury and iodide of potassium the case was one of specific disease

The question of recovery from tuberculous meningitis is one in which I am much interested, as more than 20 years ago I attended a case which was then diagnosed as tuberculous and in which also there was an affection of the apex of the left lung, and this patient, who was a boy, got well and is now working with his father as a blacksmith. The absence of tubercle in the choroid is not sufficient to negative the diagnosis, as it is only present in a small percentage of cases which are indubitably proved by post-mortem examination to be tuberculous.

Inkley.

THE LIFE SPAN OF THE GUINEA-WORM

By S. ARThur Powell, B.A., M.Ch. R.U.I., SURGEON TO THE POLICE HOSPITAL; PROFESSOR OF BIOLOGY, GRAMT MEDICAL COLLEGE, BOMBAY.

A PAPER on this subject by Sir Patrick Manson appeared last July. ${ }^{1}$ In Sir Patrick Manson's cases the time of possible infection extended from February to June. In the cases under consideration the period of exposure in the endemic area was only two days. I am indebted for the particulars to Mr. M. Cursetjee and Mr. Fazalbhoy Chinoy. A party of 16 gentlemen with five servants, all residents of Bumbay, a city with a good artificial water-supply, where guinea-worm is only seen in patients from the country, chiefly from the Deccan, left Bombay and reached Mahad on April 20th, 1902, where they all stayed for two days, drinking the water from a well without filtering it. They returned to Bombay on April 22nd. On April 2nd or 3rd, 1903, the first worm made its appearance in the leg of one of these gentlemen. Up to the first week in July worms to the number of nine continued to be discharged from bis body. Doubtless, owing to injection with perchloride of mercury, the exit of some of these worms was delayed, as they were killed, and considerable cellulitis and suppuration ensued. The next patient was delivered of a worm on May 1st, 1903, and five other patients between that date and May 20th. Seven patients in all were attacked, six of the party of 16 and one of the five servants. Nineteen worms in all were extracted. None had come out since the first week in July up to Oct. 3rd The shortest period in there cases was 345 days and the longest 435 . The great majority of the worms appeared a year and two or three weeks after the date of infection.

The est mation of the life span of this worm in its human host is a matter of importance in prognosis in the case of persons exposed to infection. Thus I had no hesitation in informing the ten gentlemen who have not yet suffered that they have little reason to fear the appearance of worms a matter of considerable apprehensin $n$ to some of them. Inquiries were made among the inhabitants of Mahad as to the prevalence of this worm in the district. The replies indicate that abnut half the population suffered from guineaworm during 1903

Two points of interest in connexion with this parasite may be mentioned here. There is frequently a considerable fever a few days before the worm becomes palpable. Two

1 Brit. Med. Jour., July 4th, 1903, p. 10. 